\title{
O perfil racial nos quadros da administração pública no Brasil: um primeiro balanço dos efeitos da reserva de vagas para negros em uma organização de segurança pública
}

\author{
Andersson Pereira dos Santos \\ Polícia Federal \\ Gilson Matilde Diana \\ Polícia Federal
}

$\mathrm{O}$ artigo analisou o perfil dos aprovados em concursos públicos promovidos por uma organização de segurança pública, com o objetivo de verificar os efeitos da ação afirmativa implementada pela Lei Federal $n^{\circ} 12.990 / 2014$, que reservou vagas para negros em processos seletivos da administração pública federal. Foram aplicados questionários socioeconômicos para 2.794 candidatos aprovados em concursos públicos promovidos pela Polícia Federal. Com base nos dados encontrados, foi constatada alteração significativa do perfil racial dos aprovados nos processos seletivos, aproximando-o do perfil racial da população brasileira. Também foi possível verificar que o benefício gerado pela ação afirmativa alcançou em menor escala os indivíduos oriundos da comunidade negra mais pobre. $O$ estudo contribui com dados empíricos que podem auxiliar os debates e subsidiar decisões políticas sobre tema tão complexo e polêmico, mas fundamental para o Estado brasileiro, que é a inclusão de segmentos desprivilegiados e discriminados da sua população.

Palavras-chave: ação afirmativa, raça - inclusão social, agente público, Brasil

[Artigo recebido em 29 de junho de 2016. Aprovado em 19 de outubro de 2018.] 
El perfil racial en la administración pública en Brasil: un primer informe sobre los efectos de la reserva de puestos para los negros en una organización de seguridad pública

El artículo analiza el perfil de aprobados en selecciones públicas promovidas por una organización de seguridad pública, con el fin de verificar los efectos de la acción afirmativa implementada por la Ley Federal № 12.990/2014, que reserva puestos para negros en procesos de selección del Gobierno Federal. Se aplicaron cuestionarios socioeconómicos a 2.794 candidatos aprobados en las selecciones públicas promovidas por la Policía Federal. Como resultado se observó una alteración significativa del perfil racial de los aprobados, acercándose al perfil racial de la población brasileña. También se observó que el beneficio generado por la acción afirmativa alcanzó en menor medida los individuos más pobre de la comunidad negro. El estudio contribuye con datos empíricos que pueden ayudar en el debate y en las decisiones políticas sobre un tema tan complejo y controvertido, pero fundamental para el Estado brasileño, que es la inclusión de segmentos desfavorecidos y discriminados de la población.

Palabras-clave: acción afirmativa, raza - inclusión social, agente público, Brasil

Racial profile in public administration in Brazil: a first report on the effects of quotas for blacks in an organization of public security

The article analyzed the profile of approved in public selections promoted by a law enforcement organization, with the objective to verify the effects of affirmative action implemented by Federal Law $\mathrm{N}^{\circ}$. 12.990/2014, that reserved places for blacks in selection processes of Federal Public Administration. Have been applied socioeconomic questionnaires to 2,794 candidates approved in public selections promoted by Federal Police. Based on data found, was observed a significant change in the racial profile of approved in the selection process, approaching the racial profile of the brazilian population. It was also observed that the benefit generated by the affirmative action reached on a smaller scale the individuals from the poorest black community. The study contributes with empirical data that can assist the debate and political decisions on a subject as complex and controversial but fundamental to the Brazilian state, which is the inclusion of underprivileged and discriminated segments of their population.

Keywords: affirmative action, race - social inclusion, public agent, Brazil 


\section{Introdução}

Nos últimos anos, o Estado brasileiro promoveu ações afirmativas com o objetivo de diminuir a desigualdade racial existente no país, especialmente a partir da inflexão institucional e política no tratamento da temática racial, que teve como corolário a criação da Secretaria Especial de Promoção da Igualdade Racial (Seppir) e a instituição da Política Nacional de Promoção da Igualdade Racial (PNPIR), no ano de 2003 (LIMA, 2010).

A Lei Federal $n^{\circ} 12.990 / 2014$, que reservou para os negros $20 \%$ das vagas oferecidas nos concursos públicos para provimento de cargos e empregos públicos, promovidos pelo Governo Federal, é uma dessas ações afirmativas, implementada com a finalidade de aproximar a composição racial dos funcionários públicos dos percentuais observados no conjunto da população brasileira, conforme disposto no texto do projeto de lei que lhe deu origem (PL n 6.738/2013).

Este artigo analisa o perfil dos candidatos aprovados em concursos públicos promovidos por uma organização de segurança pública, fazendo um balanço inicial, com o objetivo de verificar os efeitos dessa ação afirmativa na composição racial dos servidores que ingressaram no órgão por meio do primeiro concurso realizado após a edição da Lei Federal $n^{\circ} 12.990 / 2014$, bem como o levantamento de dados socioeconômicos desses novos servidores.

Para efetuar tal análise, foram utilizados dados obtidos por meio da aplicação de questionário socioeconômico com amostra de candidatos aprovados em concursos públicos promovidos pela Polícia Federal, que compuseram uma população de 2.794 indivíduos. Foi feita a comparação entre os dados obtidos com a aplicação do questionário socioeconômico em 2006 e 2007 e os dados obtidos no ano de 2015. Neste último caso, esses candidatos já foram alcançados pela Lei Federal no $12.990 / 2014$.

\section{Ações afirmativas para negros no brasil}

O ex-Ministro do Supremo Tribunal Federal Joaquim Barbosa define as ações afirmativas como políticas públicas e privadas, de caráter voluntário, facultativo ou compulsório, que são direcionadas à efetivação do princípio constitucional da igualdade material, com a finalidade de anular os efeitos da discriminação de gênero, racial, de origem nacional, de idade e de compleição física, possibilitando o efetivo oferecimento de oportunidades a que todos os seres humanos têm direito (GOMES, 2005a). 
Piovesan (2005) aponta as ações afirmativas como políticas compensatórias, tratando-se de poderoso instrumento de inclusão social, constituído por medidas especiais e temporárias, que procuram aliviar e remediar um passado de discriminação. De acordo com a autora, o objetivo das ações afirmativas é que grupos vulneráveis, como as mulheres e minorias étnicas e raciais, por exemplo, alcancem a igualdade material, o que cumpriria a finalidade pública de assegurar a pluralidade e diversidade racial, decisiva para o projeto democrático.

As estatísticas contendo os dados socioeconômicos elaboradas ao longo de 20 anos por institutos oficiais (Instituto Brasileiro de Geografia e Estatística - IBGE e Instituto de Pesquisa Econômica Aplicada - Ipea) e por instituições não oficiais (Departamento Intersindical de Estatística e Estudos Socioeconômicos - Dieese) demonstram forte desigualdade entre negros e brancos no Brasil (SANTOS; SILVA, 2006).

Apesar de representarem $51 \%$ da população brasileira, os negros permanecem sendo afetados por uma discriminação estrutural e histórica que é apresentada em diferentes graus de vulnerabilidade, possuindo níveis mais elevados de exclusão e pobreza, especialmente quando comparados com a população branca (CUNHA, 2012). Os estudos demográficos atestam as disparidades raciais entre brancos e não brancos na quantidade de anos de estudo, disparidades no acesso, permanência e finalização dos ensinos médio e superior, o que se reflete na estrutura ocupacional do mercado de trabalho (GUIMARÃES, 2006).

Piovesan (2005) afirma que se faz necessária a adoção de ações afirmativas em proveito da população negra, em especial nas áreas do trabalho e educação, uma vez que o Brasil é um país em que os afrodescendentes são $64 \%$ dos pobres e $69 \%$ dos indigentes, sendo necessário reconhecer o quadro alarmante de discriminação e exclusão social, tratando as ações afirmativas como medidas urgentes e necessárias.

O debate sobre a implantação de ações de natureza reparatória em favor da comunidade negra se iniciou com a publicação do Jornal Quilombo, editado entre 1948 e 1950, em que foi apresentada a ideia do ingresso de estudantes negros na educação privada e pública como bolsistas do Estado, no ensino secundário e superior do país, inclusive nos estabelecimentos militares (CARVALHO, 2003).

De acordo com Santos (2012), em 1968 ocorreu o primeiro registro de discussão no âmbito do Estado brasileiro do que hoje pode ser entendido como ação afirmativa voltada para os negros. Nesse ano, técnicos do Tribunal Superior do Trabalho e do Ministério do Trabalho se manifestaram favoravelmente à edição de leis que obrigassem as empresas a manterem um percentual mínimo de empregados "de cor", que variava de acordo com o ramo de atividade e demanda, para solucionar o problema da discriminação racial no mercado de trabalho. Apesar das discussões, nenhuma lei foi editada. 
$\mathrm{Na}$ década de 1970, com o designado ressurgimento do movimento negro no Brasil, foram realizados debates, passeatas, palestras e outras formas de manifestações por organizações que discutiam a questão racial, tendo sido desenvolvido relevante trabalho voltado para a exposição das desigualdades sociais entre negros e brancos, buscando a conscientização sobre o assunto e maior espaço na sociedade brasileira para o negro (CONTINS; SANT'ANA, 1996). Se convencionou chamar esse ressurgimento de "movimento negro contemporâneo", tendo se caracterizado pela ênfase em denunciar o mito da democracia racial (ALBERTI; PEREIRA, 2006).

Nos anos 1980, houve a formulação do primeiro projeto de lei voltado para combater a discriminação racial no mercado de trabalho, o PL $n^{\circ}$ 1.332/1983, apresentado pelo Deputado Federal Abdias do Nascimento, que propôs uma ação compensatória que buscava estabelecer compensações para os negros, incluindo a reserva de vagas para homens e mulheres negras na seleção para ingresso no serviço público (MOEHLECKE, 2002).

Embora tenha sido aprovado por unanimidade nas Comissões de Constituição e Justiça (CCJ), de Trabalho e Legislação Social (CTLS) e de Finanças (CF), o PL n 1.332/1983 foi arquivado em decorrência da Resolução da Câmara dos Deputados no 6, de 1989, que determinou o arquivamento das proposições de iniciativa de deputados que se encontravam em tramitação em 4 de outubro de 1988, dia anterior à promulgação da Constituição Federal de 1988.

A Constituição Federal brasileira introduziu de maneira decisiva no âmbito do Estado a questão do racismo (LoRENZo, 2012). A partir da década de 1990, a ideia sobre a implantação de ações afirmativas se tornou mais persuasiva e expressiva nos meios de comunicação de massa e rodas de discussão (GUARNIERI; MELOSILVA, 2007).

Fry (2006) destaca a existência de consenso de que houve mudança radical na política racial do Estado brasileiro a partir de 1995, com a criação de grupo de trabalho interministerial para formular atividades e políticas que visavam o reconhecimento do valor da população negra, após a pressão feita pelos movimentos negros (OLIVEIRA; LIMA; SANTOS, 1998). Nesse ano foram realizadas manifestações comemorativas referentes aos 300 anos da morte de Zumbi, que culminaram com a Marcha Zumbi dos Palmares, realizada em Brasília, tendo sido entregue ao Presidente Fernando Henrique um documento com as principais reivindicações do Movimento Negro (SANTOS; MACHADO, 2008).

Em 1996 foi publicado o Programa de Direitos Humanos, que dedicou um capítulo à comunidade negra, propondo, inclusive, ações da iniciativa privada que realizassem discriminação positiva, ações afirmativas para facilitar o acesso 
de negros à educação e políticas compensatórias que promovessem social e economicamente a população negra (MARTINS, 1996; FRY, 2006).

A mudança da política racial se intensificou a partir da intensa preparação para a participação na III Conferência Mundial das Nações Unidas de Combate ao Racismo, Discriminação Racial, Xenofobia e Intolerância Correlata, realizada em 2001, na cidade de Durban, na África do Sul (HERINGER, 2001; MAIO; SANTOS, 2005; FrY, 2006; AlBerTI; PereirA, 2006; LIMA, 2010). Foi criado um comitê nacional que organizou pré-conferências em diversos estados brasileiros com a finalidade de debater aspectos importantes para o Brasil na agenda da conferência mundial, culminando com os debates ocorridos na conferência nacional, que subsidiaram a formulação do documento Plano Nacional de Combate ao Racismo e a Intolerância - Carta do Rio, encaminhado à conferência mundial (MOURA; BARRETO, 2002).

A conferência foi uma referência mundial na luta antirracista, com reflexos internos no país, tendo o governo brasileiro se comprometido a lutar contra a discriminação racial (SOUSA; PORTES, 2011). Em 2002 foi lançado o Programa Nacional de Direitos Humanos II, que apresentou um conjunto de medidas voltadas para a promoção dos direitos da população negra (DOMINGUES, 2005), e o Programa Nacional de Ações Afirmativas, sob a coordenação da Secretaria de Estado dos Direitos Humanos do Ministério da Justiça (LIMA, 2010).

A criação da Secretaria Especial de Promoção da Igualdade Racial (Seppir) em 2003, após a conferência mundial, com atribuição de formular, coordenar e articular políticas e diretrizes para a promoção da igualdade racial voltada para a consolidação do tema da igualdade racial, teve efeitos políticos no desenho de ações governamentais, causando mudanças profundas na condução de políticas públicas elaboradas com perspectiva racial, incluindo o debate sobre a implementação de cotas para negros (LIMA, 2010).

A implantação do sistema de cotas para negros em vários campos da vida social, incluindo a reserva de vagas em concursos públicos e em universidades públicas, estava prevista na redação original do Projeto de Lei $n^{\circ} 3.198 / 2000$, mas não foi contemplada no texto da Lei Federal $n^{\circ}$ 12.288/2010 (Estatuto da Igualdade Racial), publicada após mais de 10 anos de debates do projeto pelo Congresso Nacional (SILVA, 2012).

Até a edição da Lei $n^{\circ} 12.711 / 2012$, que instituiu a reserva de vagas no sistema de educação superior e do ensino médio federal para pretos, pardos e indígenas, esta ação afirmativa tinha um caráter fragmentado, tendo sido disseminada pelo Brasil ao longo de mais de 10 anos, de modo heterogêneo, por meio de iniciativas locais, como a deliberação de conselhos universitários e leis estaduais, tendo 
se iniciado em universidades estaduais do Rio de Janeiro, no ano de 2001, com bastante repercussão na opinião pública (DAFLON; FERES JUNIOR; CAMPOS, 2013).

No campo do trabalho, a principal iniciativa foi a edição da Lei Federal $n^{\circ}$ $12.990 / 2014$, que reservou $20 \%$ das vagas oferecidas em concursos públicos promovidos pela administração pública federal para os negros, tratando-se de uma ação afirmativa com bastante repercussão na imprensa nacional.

\section{Reserva das vagas oferecidas nos concursos públicos brasileiros para candidatos negros}

O grau de competitividade pelo emprego público no Brasil é alto, havendo uma forte concorrência na busca pelos postos de trabalho do setor público (NOGUEIRA, 2005). A política remuneratória da administração pública federal tem sido eficiente para atrair novos funcionários em razão dos bons salários pagos aos seus servidores (MARCONI, 2003). Os empregados do setor público no Brasil tendem a receber rendimentos superiores aos empregados da iniciativa privada, assim como ocorre em outros países, mesmo quando são comparados trabalhadores com semelhantes atributos e características (MARCONI, 2003; SOUZA; MEdEIROS, 2013).

Além da remuneração, a estabilidade também é buscada por quem almeja ingressar no serviço público, especialmente diante das dificuldades em se lidar com a instabilidade do mercado de trabalho (SILVA, 2004; SILVA; BALASSIANO; SILVA, 2014). Os concursos públicos são uma maneira de se obter a inserção no serviço público, possibilitando o alcance da garantia de estabilidade financeira (RIBEIRO; MANCEBO, 2009; ALBRECHT; KRAWULSKI, 2011). A busca por um emprego estável alimenta uma cadeia milionária de negócios, incluindo a publicação de livros, venda de apostilas e cursinhos preparatórios direcionados para a preparação de concursos (RIBEIRO; MANCEBO, 2013).

Desde a organização do Departamento Administrativo do Serviço Público (Dasp) em 1938, com a atribuição de definir e executar a política para o pessoal civil, inclusive a admissão mediante concurso público (COSTA, 2008), os processos seletivos para ingresso em cargos públicos possuem duas finalidades: assegurar a observância do princípio da isonomia e promover a seleção dos concorrentes mais capacitados para o exercício de funções (CAMMAROSANO, 1984).

Os concursos públicos são pautados por duas ideologias: a ideologia acadêmica, que busca recrutar os melhores egressos do sistema de ensino; e a ideologia profissional, que busca recrutar os profissionais mais competentes, que já demonstrem as habilidades necessárias ao exercício do futuro cargo (FonTAINHA; Geraldo; Veronese; Alves, 2015). Como consequência, de maneira geral, os 
servidores públicos que trabalham no Governo Federal possuem boa escolaridade, sendo certo que grande parte possui a graduação em nível superior (OLIVEIRA, 2007).

Em pesquisa que teve como objetivo investigar os fatores que possibilitam o sucesso em concursos públicos, Castelar, Veloso, Ferreira e Soares (2010) avaliaram o perfil dos candidatos que foram aprovados e tomaram posse em cargos públicos. Segundo os autores, a probabilidade de aprovação nos certames foi definida em função das características socioeconômicas dos candidatos, tendo sido constatado que a alta renda familiar e uma maior escolaridade são fatores que aumentam a chance de sucesso nas seleções públicas. Em sentido oposto, a renda abaixo de dois salários mínimos e a baixa escolaridade contribuem para uma menor chance de aprovação nos concursos públicos.

Em razão da desigualdade nas condições de formação e preparação, assim como na condição de vida mais precária vivenciada pela população negra, apesar dos critérios considerados impessoais de seleção para cargos públicos, há um evidente acesso desigual ao emprego no serviço público (SILVA; SILVA, 2014). A desigualdade social entre negros e brancos possui forte relação com a inserção profissional, tendo impacto na desigualdade de acesso a oportunidades profissionais no mercado de trabalho, em vista da menor condição econômica e do menor grau de escolaridade dos negros, dificultando o acesso destes ao emprego no setor público (ESTANISLAU; GOMOR; NAIME, 2015).

Segundo Domingues (2005), existiam apenas dez negros entre mil diplomatas no Itamaraty e o contingente de médicos, oficiais, engenheiros, professores universitários negros era ínfimo no país. Carvalho (2003), em artigo no qual discute a utilização das ações afirmativas como resposta ao racismo no meio acadêmico, elenca as dificuldades de acesso de negros aos cargos de professores universitários. De acordo com Carvalho (2001), em cem anos de vida universitária dos negros no Brasil, não chegava a $1 \%$ o número de professores negros.

No Censo do Poder Judiciário, realizado no ano de 2013 pelo Conselho Nacional de Justiça, foi verificado que, dos magistrados brasileiros, apenas $14 \%$ se declararam pardos, $1,4 \%$ pretos e $0,1 \%$ indígenas, totalizando apenas $15,4 \%$ de negros (pretos e pardos) (SILVEIRA, 2015). Entre os servidores do Poder Judiciário, a presença de negros é maior nos tribunais superiores $(37,2 \%)$ e menor na justiça federal $(24,0 \%)$ (CONSELHo NACIONAL DE JUSTIÇA, 2014).

Em uma pesquisa realizada junto à Polícia Militar da Bahia, Ramalho Neto (2012) construiu um "mapa racial" da corporação, verificando que, apesar do ingresso de indivíduos "de cor" ou pigmentados no quadro de oficiais se iniciar a partir do final da década de 1960, não significou a absorção equilibrada de pessoas oriundas das camadas mais populares de origem ético-racial descendentes de africanos. 
Em levantamento realizado junto aos servidores públicos federais, foi constatada que a distribuição de servidores do Poder Executivo Federal, segundo a raça/cor, indica a presença de $22,4 \%$ de pardos e $4 \%$ de pretos, totalizando apenas $26,4 \%$ de negros (pretos e pardos) trabalhando em órgãos da administração direta, autarquias e fundações mantidas pela União (ESCOLA NACIONAL DE ADMINISTRAÇÃo PúBLICA, 2014). Esses números, quando comparados à população residente no país, composta por $45,5 \%$ de pardos e $8,6 \%$ de pretos, que totalizam $54,1 \%$ de negros (INSTITUTO BRASILEIRO DE GEOGRAFIA E ESTATístICA, 2015), demonstram que a população negra se encontra, proporcionalmente ao seu quantitativo existente no país, sub-representada no quadro de servidores do Poder Executivo federal.

Com o objetivo de alterar tal quadro, buscando aproximar a composição racial dos servidores da administração pública federal dos percentuais observados no conjunto da população brasileira, foi enviado ao Congresso Nacional o Projeto de Lei $n^{\circ}$ 6.738/2013, que deu origem à Lei Federal $n^{\circ}$ 12.990/2014 (SILVA; SILVA, 2014). A lei, publicada em junho de 2014, com vigência de dez anos, reservou $20 \%$ das vagas de concursos públicos promovidos no âmbito da administração pública federal para candidatos negros. A norma federal estabelece que podem concorrer às vagas reservadas aqueles que se autodeclararem pretos ou pardos no ato da inscrição no concurso público, conforme o quesito cor ou raça utilizado pelo IBGE (BRASIL, 2014).

A Lei Federal $n^{\circ}$ 12.990/2014 estabeleceu que os candidatos negros concorrem concomitantemente às vagas reservadas e às vagas destinadas à ampla concorrência. Os candidatos negros aprovados dentro do número de vagas oferecido para ampla concorrência não serão computados para efeito do preenchimento das vagas reservadas (BRASIL, 2014), o que, em tese, amplia o ingresso de pessoas negras no serviço público.

Com a publicação da Lei Federal $n^{\circ}$ 12.990/2014, é esperado que ocorra a reversão da disparidade que existe entre as características da população brasileira e as dos servidores da administração pública federal, permitindo o ingresso de pretos e pardos em empregos públicos em número proporcional ao existente na população do Brasil, onde somam mais da metade da população (ESTANISLAU; GOMOR; NAIME, 2015).

\section{A eficácia da reserva de vagas para a diminuição das desigualdades sociais}

Uma parcela da literatura discute a eficácia das cotas para negros como fator da diminuição das desigualdades sociais. Autores destacam que, embora seja importante a instituição de ações afirmativas para o combate ao racismo, não se 
pode esperar que a sua aplicação isoladamente reduza a pobreza da população negra ou resolva o problema do racismo.

Uma das restrições apresentadas por críticos das cotas raciais é o chamado efeito creamy layer, segundo o qual a reserva de vagas termina por beneficiar predominantemente os integrantes de um determinado grupo racial com melhores condições socioeconômicas, por exemplo, negros ricos beneficiados em uma política de cotas baseada somente em cor ou raça (MENDES JUNIOR; WALTENBERG, 2013).

Do mesmo modo em que a Índia foi o primeiro país a utilizar políticas de ação afirmativa, foi lá que surgiu a expressão creamy layer, utilizada para nominar as pessoas beneficiadas por uma dessas políticas, mas que já teriam, supostamente, vantagens competitivas na seleção para ingresso em universidades ou para obtenção de emprego e que não precisariam de medidas especiais como estas (FERES JúNIOR; DAFLON, 2015a).

Feres Júnior e Daflon (2015a) destacam que não existe consenso sobre os efeitos empíricos ou sobre a questão normativa do creamy layer na Índia ou nos Estados Unidos, e que essa discussão chegou ao Brasil por meio da grande imprensa. No entanto, de acordo com os autores, os resultados reais da aplicação das leis que instituíram cotas carecem de avaliações cuidadosas, que sejam feitas a partir de dados empíricos.

Ao analisar as opiniões contrárias às políticas de ação afirmativa em universidades públicas veiculadas pela mídia brasileira, Feres Júnior (2008) aponta que, para que essas políticas não resultem em privilégio de negros de classe média, se faz necessário combinar o critério raça/cor com o critério renda, ou da escola pública, que funcionaria como proxy para a renda, garantindo-se que os beneficiários não brancos não fossem oriundos da classe média.

Por outro lado, o autor ressalta que os cursos mais competitivos das universidades públicas de melhor qualidade são, na prática, dominados por brancos de classes alta e média, o que dificultaria justificar porque os não brancos de classe média deveriam ter seu acesso barrado às políticas de ação afirmativa, que possibilitam o acesso a essas posições, consideradas de prestígio (FERES JúNIOR, 2008).

Em 1996, quando a discussão sobre a implementação de ações afirmativas no Brasil ainda era incipiente, Guimarães (1996) afirmava que era óbvio que uma política de cotas, envolvendo o acesso ao ensino superior, a posições de direção em empresas e autarquias, a contratos públicos de prestação de serviços, entre outros, beneficiaria a um conjunto restrito da comunidade negra, incorporado à classe média, por se tratar daqueles que possuem a qualificação e a capacitação requeridas para tais postos. O autor defendia que as políticas dessa natureza deveriam estar associadas a outras, voltadas para a universalização e melhoria 
do ensino público fundamental e médio, a assistência médica e odontológica e as condições sanitárias, ampliando a cidadania da população pobre.

No mesmo sentido, Azevedo (2004) alerta que a implantação progressiva de cotas raciais pelo Estado nas diversas áreas da sociedade civil não pode ser considerada como a única opção para a resolução do problema do racismo institucional e da pobreza de grande parcela da comunidade negra. Para Pereira e Zientarski (2011), a resolução do problema da exclusão por meio de ações afirmativas de raça e gênero seriam ações paliativas, compensatórias e imediatistas que camuflariam o problema. As autoras defendem que a solução deve estar calcada em ações afirmativas aplicadas por meio de políticas sociais em todas as áreas, e, entre estas, a educação de base voltada para a equidade e a qualidade.

Haas e Linhares (2012), em artigo que analisa a aplicação de ações afirmativas para ingresso na educação superior, apontam que o estudante negro pobre é diferente do branco pobre, pois, enquanto o branco é discriminado pela sua condição socioeconômica, o negro é discriminado duas vezes, pela condição socioeconômica e racial. Assim, nessas circunstâncias, as cotas em universidades propiciariam vantagens aos negros que estão misturados aos brancos na classe média baixa brasileira, que são excluídos no funil do vestibular tradicional em razão das deficiências na formação básica associadas a práticas discriminatórias, e não beneficiam os negros pobres, que vivem nos limites da pobreza e não possuem qualquer aspiração ao curso superior (HAAS; LINHARES, 2012).

No entanto, Haas e Linhares (2012) concluem destacando que, na discussão sobre o sistema de cotas para ingresso em universidades públicas brasileiras, deve-se atender às pessoas discriminadas, independentemente da sua condição socioeconômica, como uma forma de se combater o preconceito, que é um problema presente no Brasil.

Alberti e Pereira (2006), quando analisaram as discussões acerca da implantação de cotas para ingresso nas universidades públicas, relataram que muitas das lideranças do movimento negro afirmavam que o tema das cotas não era solução para tudo, devendo ser vista como medida emergencial. No entanto, os autores destacaram que a maior riqueza da implantação das cotas estava no debate e nas mudanças que a implantação de tal medida seria capaz de implementar.

Neste sentido, Tragtenberg (2002) considera que as ações afirmativas não resolverão o problema do racismo cordial brasileiro, mas no mínimo irão chamar a atenção dos brasileiros para ele e provavelmente irão minorá-lo, pois, apenas uma melhora sensível nos níveis de emprego, na distribuição de renda e nas políticas sociais poderia contribuir de forma permanente para a melhoria do padrão de vida dos brasileiros, particularmente os negros. 
Segundo Azevedo (2004), existe uma afirmação constante nos Estados Unidos de que as políticas de ação afirmativa beneficiaram principalmente a classe média negra, sem solucionar os problemas da pobreza da maior parte da comunidade negra americana, o que foi corroborado por dados da sociedade norte-americana apresentados por Andrews (1997). No entanto, Walters (1997) afirma que não se pode cobrar da ação afirmativa a diminuição da pobreza das classes inferiores, pois este nunca foi o seu objetivo exclusivo. Ou seja, a implementação de cotas raciais, embora auxilie na diminuição da discriminação racial e no combate ao racismo, por si só, não é suficiente para reduzir a pobreza da comunidade negra.

Feres Júnior e Daflon (2015b) afirmam que está cedo para avaliar se as ações afirmativas falham em reduzir as desigualdades no Brasil, pois essas políticas estão em vigor há pouco mais de 10 anos. De acordo com os autores, a adoção de uma abordagem pragmática em relação à elaboração e implementação das ações afirmativas que instituíram as cotas é uma opção mais razoável, uma vez que estas podem ser aperfeiçoadas por meio de um trabalho contínuo de avaliação e reformulação das suas premissas, métodos e procedimentos se os resultados apontarem pela necessidade de modificações na política.

\section{Método}

Com o objetivo de verificar se houve mudança do perfil racial dos candidatos aprovados em concursos públicos promovidos após a edição da Lei n 12.990/2014, foram analisados os dados dos candidatos aprovados em processos seletivos para provimento de cargos policiais promovidos pela Polícia Federal, organização de segurança pública que está distribuída e atua em todo o território nacional, contribuindo com a manutenção da lei e da ordem e preservação do Estado democrático de direito.

O nível de escolaridade exigido para ingresso nos cargos policiais é a graduação em nível superior. O número de inscritos nos últimos processos seletivos realizados pela instituição tem superado, nos últimos 10 anos, a média de 100.000 inscritos, com demanda de candidato por vaga superior a 100, tratando-se de uma das seleções mais concorridas do Brasil.

Os concursos públicos são divididos em duas etapas. A primeira etapa é composta por provas objetivas, discursivas, exame de aptidão física, avaliação psicológica e exames médicos, aplicados em todas as capitais do país. A segunda etapa consiste em curso de formação, de caráter eliminatório, realizado na Academia Nacional de Polícia, no qual somente são matriculados os candidatos aprovados na primeira etapa do concurso público e classificados dentro do número de vagas previsto em edital. 
$\mathrm{Na}$ maioria das iniciativas voltadas para a implementação das políticas de ação afirmativa, não se verifica a existência de instrumentos consolidados de acompanhamento e avaliação, resultando em limitada oferta de dados sistematizados, o que dificulta o seu monitoramento (SILVA; SILVA, 2014). Na Polícia Federal, não existem dados consolidados sobre a cor dos seus integrantes. Com a finalidade de suprir tal lacuna, para a realização do estudo, foi utilizado um conjunto de informações coletadas junto aos candidatos que foram matriculados em cursos de formação.

Os dados foram coletados, com autorização da organização, por meio da aplicação de questionário que permitiu conhecer o perfil socioeconômico dos candidatos matriculados em quatro cursos de formação realizados pela Academia Nacional de Polícia, ministrados no segundo semestre de 2006, nos primeiro e segundo semestres de 2007, antes, portanto, da edição da Lei n 12.990/2014, e no segundo semestre de 2015, após a implementação da ação afirmativa. Não foram aplicados questionários em outros cursos de formação.

Os questionários foram preenchidos em papel pelos candidatos nos cursos de formação realizados em 2006 e 2007. Os dados foram inseridos num banco de dados do Statistical Package for the Social Science (SPSS), versão 21.0. No curso de formação realizado em 2015, o link contendo o endereço eletrônico dos questionários foi enviado para todos os candidatos matriculados no curso de formação, que receberam as orientações dos instrutores para o seu preenchimento.

Compuseram o estudo 2.794 participantes, matriculados em cursos de formação, que responderam o questionário, distribuídos em 650 no curso realizado no segundo semestre de 2006, 761 no primeiro semestre de 2007,719 no segundo semestre de 2007 e 664 no segundo semestre de 2015. Os dados foram analisados com a utilização do SPSS.

A comparação entre as informações de cor/raça referentes aos cursos de formação estudados, bem como dos indicadores socioeconômicos, foi feita por meio do teste Qui-quadrado para proporções, com a aplicação de testes post hoc para identificar quais "grupos raciais" apresentavam diferenças entre si. O nível de significância de $p<0,05$ foi adotado em todas as análises.

Apesar de o sistema de classificação de cor/raça (branco, preto, pardo, amarelo e indígena) adotado pelo IBGE ser alvo de controvérsias entre sociólogos e antropólogos (VAlle Silva, 1999; SchWARTZMAN, 1999; WoOd; CARVAlHO; HoRTA, 2010; LoVEMAN; MunIZ; BAILEY, 2011; ANJOS, 2013), este foi o sistema adotado no presente trabalho, tendo sido denominadas negras as pessoas classificadas como pretas ou pardas, conforme os censos demográficos realizados pelo instituto 
(Rosemberg, 2004; GoMes, 2005b; ANJos, 2013). O critério para definição da cor/ raça foi a autodeclaração.

Justifica-se agregar os pretos e pardos para formar o grupo racial negro, tendo em vista que a situação dos dois "grupos raciais" é semelhante no tocante à obtenção de vantagens sociais e outros importantes benefícios e bens, assim como em termos de exclusão dos seus direitos legais e legítimos, bem distantes ou desiguais quando comparados à situação do grupo racial branco (SANTOS, 2002, GUIMARÃES, 2006), bem como em razão das discriminações experimentadas por ambos os grupos serem da mesma natureza, ou seja, associadas a barreiras de cor (OsóRIO, 2003).

\section{Cor/raça dos candidatos aprovados}

A análise da cor/raça dos candidatos aprovados no concurso público foi realizada com base nas respostas oferecidas pelos candidatos à pergunta "Qual é a sua cor ou raça?". As opções de resposta existentes no questionário foram: branca, preta, amarela, parda e indígena. A Tabela 1 apresenta o perfil racial dos candidatos matriculados nos cursos de formação realizados pela Polícia Federal, elaborada a partir das respostas oferecidas pelos candidatos:

\section{Tabela 1 - Cor/raça dos candidatos matriculados nos cursos de formação}

\begin{tabular}{|c|c|c|c|c|c|c|c|c|}
\hline \multirow{3}{*}{ Cor/raça } & \multicolumn{8}{|c|}{ Cursos de formação } \\
\hline & \multicolumn{2}{|c|}{2006.2} & \multicolumn{2}{|c|}{2007.1} & \multicolumn{2}{|c|}{2007.2} & \multicolumn{2}{|c|}{2015.2} \\
\hline & $\mathrm{n}$ & $\%$ & $\mathrm{n}$ & $\%$ & $\mathrm{n}$ & $\%$ & $n$ & $\%$ \\
\hline Branca & 466 & 71,69 & 582 & 76,48 & 487 & 67,37 & 312 & 46,99 \\
\hline Parda & 131 & 20,15 & 125 & 16,43 & 170 & 23,64 & 268 & 40,36 \\
\hline Amarela & 19 & 2,92 & 21 & 2,76 & 15 & 2,09 & 15 & 2,26 \\
\hline Preta & 19 & 2,92 & 19 & 2,50 & 20 & 2,78 & 51 & 7,68 \\
\hline Indígena & 1 & 0,15 & 0 & 0,00 & 6 & 0,83 & 0 & 0,00 \\
\hline Sem declaração & 14 & 2,15 & 14 & 1,84 & 21 & 2,92 & 18 & 2,71 \\
\hline Total & 650 & & 761 & & 719 & & 664 & \\
\hline
\end{tabular}

Fonte: elaboração própria.

Com base nos dados obtidos, foi observada uma diferença significativa da composição racial dos candidatos matriculados no curso de formação realizado após a edição da Lei $n^{\circ} 12.990 / 2014\left(\chi^{2}(3)=172,93 ; p<0,05\right)$, especialmente de brancos, pardos e negros, como pode ser observado no Gráfico 1: 


\section{Gráfico 1 - Cor/raça dos participantes dos Cursos de Formação - valores percentuais}

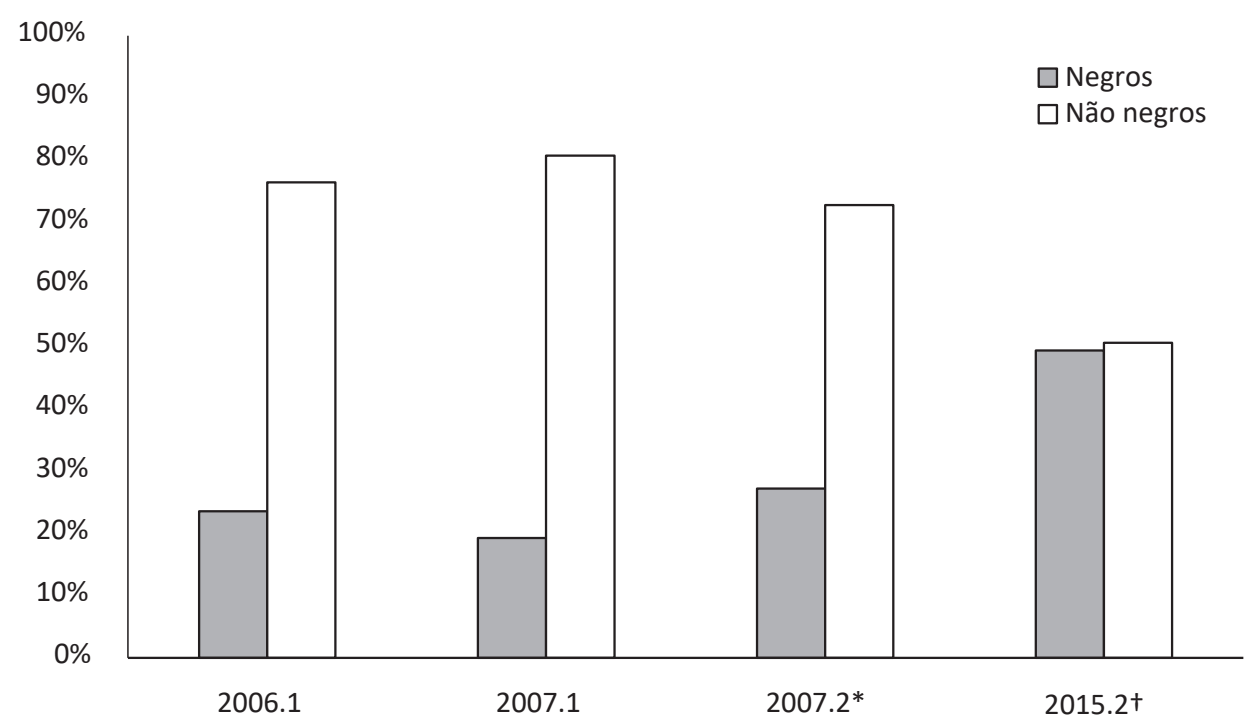

Fonte: elaboração própria.

* Proporções significativamente diferentes $(p<0,05)$ das proporções registradas em 2007.1. † Proporções significativamente diferentes $(p<0,05)$ das proporções registradas em 2006.1, 2007.1 e 2007.2.

O percentual de candidatos negros matriculados nos cursos de formação realizados antes da edição da Lei $n^{\circ} 12.990 / 2014$, descrito na Tabela 1, se assemelha ao levantamento realizado junto aos servidores públicos federais pela Enap (2014), no qual foi registrada a presença de $22,4 \%$ de pardos e $4 \%$ de pretos, totalizando apenas $26,4 \%$ de negros (pretos e pardos) trabalhando em órgãos da administração direta, autarquias e fundações mantidas pela União. Desse modo, foi constatada a sub-representação de negros entre os matriculados nos cursos de formação realizados em 2006 e 2007, quando comparado ao perfil racial da sociedade brasileira, assim como no estudo feito pela Enap.

No primeiro curso de formação realizado após a implementação da política afirmativa, em 2015, observou-se que o percentual de candidatos pardos e pretos (Tabela 1) se aproximou do perfil da população brasileira, composta por $45,5 \%$ de pardos e $8,6 \%$ de pretos, que totalizam $54,1 \%$ de negros (INSTITUTO BRASILEIRO DE GEOGRAFIA E ESTATÍ́sTICA, 2015). O percentual de candidatos negros (pardos e pretos) subiu para $48,04 \%$ em 2015 , contrastando com os $23,07 \%$ do segundo semestre de $2006,18,93 \%$ do primeiro semestre de 2007 e $26,42 \%$ do segundo semestre de 2007. O percentual de candidatos que declarou possuir a cor/raça amarela se manteve estável, entre $2 \%$ e $3 \%$. 
Em adendo à pergunta formulada sobre a cor/raça, foi questionado aos candidatos se eles se declaravam negros. O objetivo do questionamento foi o de verificar se os candidatos pardos se identificam como parte da comunidade negra, tendo sido obtidas as respostas expressas na Tabela 2 .

Tabela 2 - Resposta dos candidatos que se declararam pardos à pergunta "Você se declara negro?"

Cursos de formação

\begin{tabular}{|c|c|c|c|c|c|c|c|c|}
\hline \multirow{2}{*}{$\begin{array}{l}\text { Você se declara } \\
\text { negro? }\end{array}$} & \multicolumn{2}{|c|}{2006.2} & \multicolumn{2}{|c|}{2007.1} & \multicolumn{2}{|c|}{2007.2} & \multicolumn{2}{|c|}{2015.2} \\
\hline & $n$ & $\%$ & $\mathrm{n}$ & $\%$ & $n$ & $\%$ & $\mathrm{n}$ & $\%$ \\
\hline Sim & 19 & 14,50 & 21 & 16,80 & 43 & 25,29 & 172 & 64,18 \\
\hline Não & 112 & 85,50 & 104 & 83,20 & 127 & 74,71 & 93 & 34,70 \\
\hline Sem declaração & 0 & 0,00 & 0 & 0,00 & 0 & 0,00 & 3 & 1,12 \\
\hline Total & 131 & & 125 & & 170 & & 268 & \\
\hline
\end{tabular}

Nos cursos de formação realizados em 2006 e 2007, o percentual de candidatos pardos que se declaravam como negros era baixo, tendo sido observado que $14,50 \%$ dos pardos que participaram do curso no segundo semestre de 2006 se declaravam negros, $16,80 \%$ no primeiro semestre de 2007 e $25,29 \%$ no segundo semestre de 2007. No curso realizado no segundo semestre de 2015 , o percentual de candidatos pardos que se declarou negro subiu para $64,18 \%$.

Com base nos dados colhidos, se pôde observar uma alteração significativa ( $\chi 2$ (3) $=149,00 ; p<0,05)$ nas respostas oferecidas pelos candidatos que se declararam pardos nos cursos de formação realizados antes e depois da implementação da ação afirmativa. Verificou-se uma tendência do aumento do número de candidatos pardos que passaram a se reconhecer como negros, como pode ser visualizado no Gráfico 2. 
Gráfico 2 - Resposta dos candidatos que se declararam pardos à pergunta "Você se declara negro?" - Valores percentuais

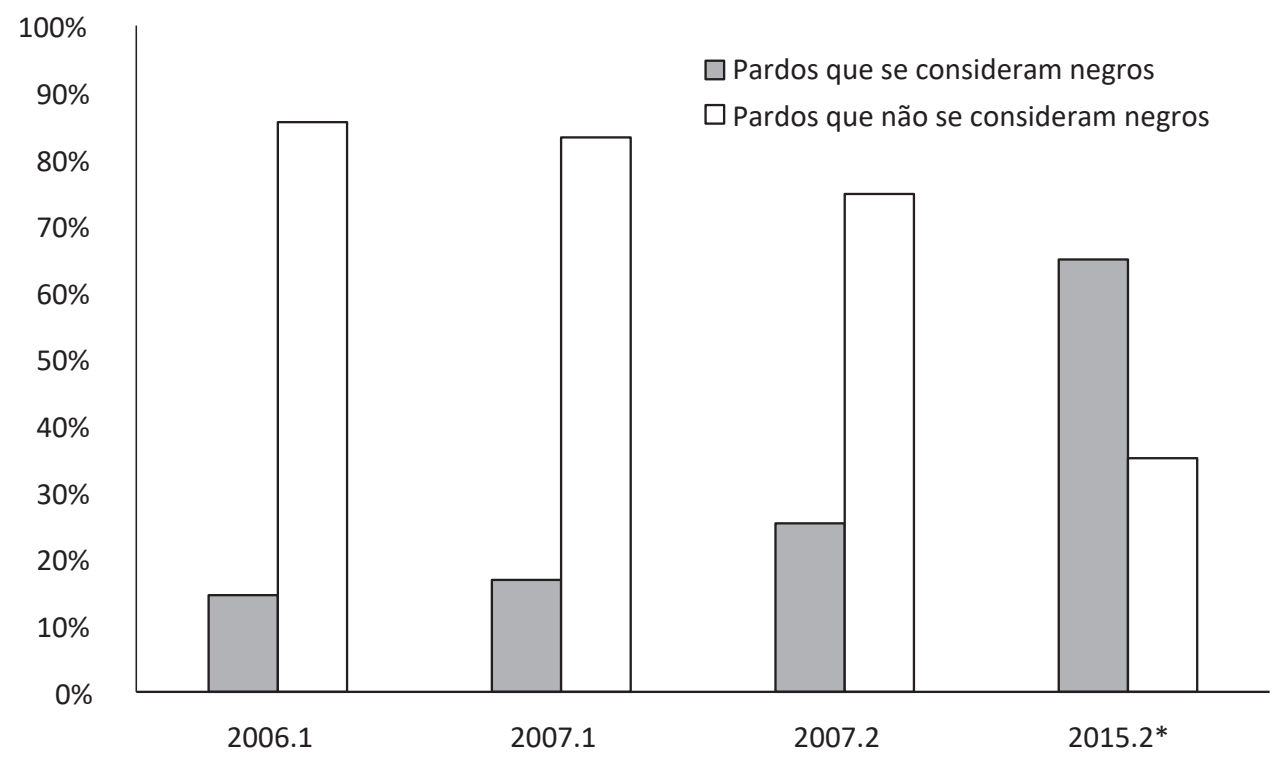

Fonte: elaboração própria.

* Proporções significativamente diferentes $(p<0,05)$ das proporções registradas em 2006.1, 2007.1 e 2007.2.

\section{Características socioeconômicas dos candidatos aprovados}

Com a finalidade de se conhecer o perfil socioeconômico dos candidatos aprovados no concurso público promovido após a publicação da Lei n 12.990/2014, foram analisadas as respostas oferecidas pelos candidatos às perguntas presentes no questionário sobre a renda familiar, tipo de residência da família, nível de escolaridade dos pais e tipo de estabelecimento de ensino nos quais os candidatos cursaram o ensino médio e o nível superior.

Os candidatos foram separados em três grupos: (1) brancos e amarelos (não negros) ( $\mathbf{n}=327$ candidatos); (2) negros (pardos e pretos) aprovados na ampla concorrência ( $\mathbf{n}=\mathbf{2 1 0}$ candidatos); e (3) negros (pardos e pretos) beneficiados pela reserva de vagas ( $\mathbf{n}=109$ candidatos). Os 18 candidatos que não declararam a sua cor/raça foram excluídos da análise. O objetivo foi verificar se os candidatos negros beneficiados pela reserva de vagas possuíam índices socioeconômicos inferiores aos candidatos brancos e amarelos ou mesmo aos candidatos negros aprovados sem o benefício da ação afirmativa. 
As opções de resposta à pergunta sobre a renda familiar foram baseadas no salário mínimo vigente no período de realização do curso de formação, no ano de 2015, cujo valor era de $\mathrm{R} \$ \mathbf{7 8 8 , 0 0}$ (setecentos e oitenta e oito reais). Os resultados obtidos, apresentados na Tabela 3, demonstram que o nível de renda dos candidatos negros beneficiados pela ação afirmativa se mostrou, em média, inferior ao dos candidatos negros aprovados na lista ampla, que, por sua vez, foi inferior à renda dos candidatos brancos e amarelos. No entanto, quando aplicado o teste estatístico, não foi verificada diferença significativa entre a distribuição de renda dos candidatos brancos e amarelos, negros e negros beneficiados pela ação afirmativa $\left(\chi^{2}(14)=18,90 ; p>0,05\right)$.

Verificou-se que $71,56 \%$ dos negros beneficiados pela reserva de vagas foram oriundos de famílias com renda mensal superior a 5 salários mínimos ( $R \$ 3.940,00$ ), incluindo 29,36\% com renda familiar superior a 10 salários mínimos ( $R \$ 7.880,00$ ), como pode ser visto na Tabela 3. Pode-se constatar, portanto, que a ação afirmativa beneficiou em menor proporção os integrantes da comunidade negra com renda mais baixa, tendo apenas $11,01 \%$ dos candidatos com renda familiar igual ou inferior a 3 salários mínimos.

\section{Tabela 3 - Renda familiar}

\begin{tabular}{|c|c|c|c|c|c|c|}
\hline \multirow[t]{2}{*}{ Renda } & \multicolumn{2}{|c|}{$\begin{array}{l}\text { Brancos e } \\
\text { amarelos }\end{array}$} & \multicolumn{2}{|c|}{ Negros } & \multicolumn{2}{|c|}{$\begin{array}{c}\text { Negros } \\
\text { beneficiados } \\
\text { pela ação } \\
\text { afirmativa }\end{array}$} \\
\hline & $\mathrm{n}$ & $\%$ & $\mathrm{n}$ & $\%$ & $\mathrm{n}$ & $\%$ \\
\hline $\mathrm{R} \$ 788,00$ & 2 & 0,61 & 2 & 0,95 & 0 & 0,00 \\
\hline De $\mathrm{R} \$ 788,01$ até $\mathrm{R} \$ 2.364,00$ & 11 & 3,36 & 12 & 5,71 & 12 & 11,01 \\
\hline De $R \$ 2.364,01$ até $R \$ 3.940,00$ & 41 & 12,54 & 38 & 18,10 & 19 & 17,43 \\
\hline De $\mathrm{R} \$ 3.940,01$ até $\mathrm{R} \$ 7.880,00$ & 129 & 39,45 & 80 & 38,10 & 46 & 42,20 \\
\hline De $\mathrm{R} \$ 7.880,01$ até $\mathrm{R} \$ 11.820,00$ & 63 & 19,27 & 40 & 19,05 & 15 & 13,76 \\
\hline De $\mathrm{R} \$ 11.820,01$ até $\mathrm{R} \$ 15.760,00$ & 43 & 13,15 & 21 & 10,00 & 9 & 8,26 \\
\hline De $\mathrm{R} \$ 15.760,01$ até $\mathrm{R} \$ 23.640,00$ & 24 & 7,34 & 12 & 5,71 & 6 & 5,50 \\
\hline Mais de $\mathrm{R} \$ 23.640,00$ & 12 & 3,67 & 5 & 2,38 & 2 & 1,83 \\
\hline Não declarado & 2 & 0,61 & 0 & 0,0 & 0 & 0,00 \\
\hline Total & 327 & & 210 & & 109 & \\
\hline
\end{tabular}

Fonte: elaboração própria. 
No tocante ao tipo de residência dos candidatos, a proporção de candidatos brancos e amarelos que possuem casa própria quitada é superior à dos negros, que é, por sua vez, maior que a dos negros beneficiados pela reserva de vagas. Nesse sentido, foi verificada diferença significativa entre os candidatos brancos e amarelos e os candidatos negros beneficiados pela ação afirmativa $\left(\chi^{2}(6)=18,90 ; p<0,05\right)$, como pode ser visto no Gráfico 3.

\section{Gráfico 3 - Tipo de residência dos candidatos}

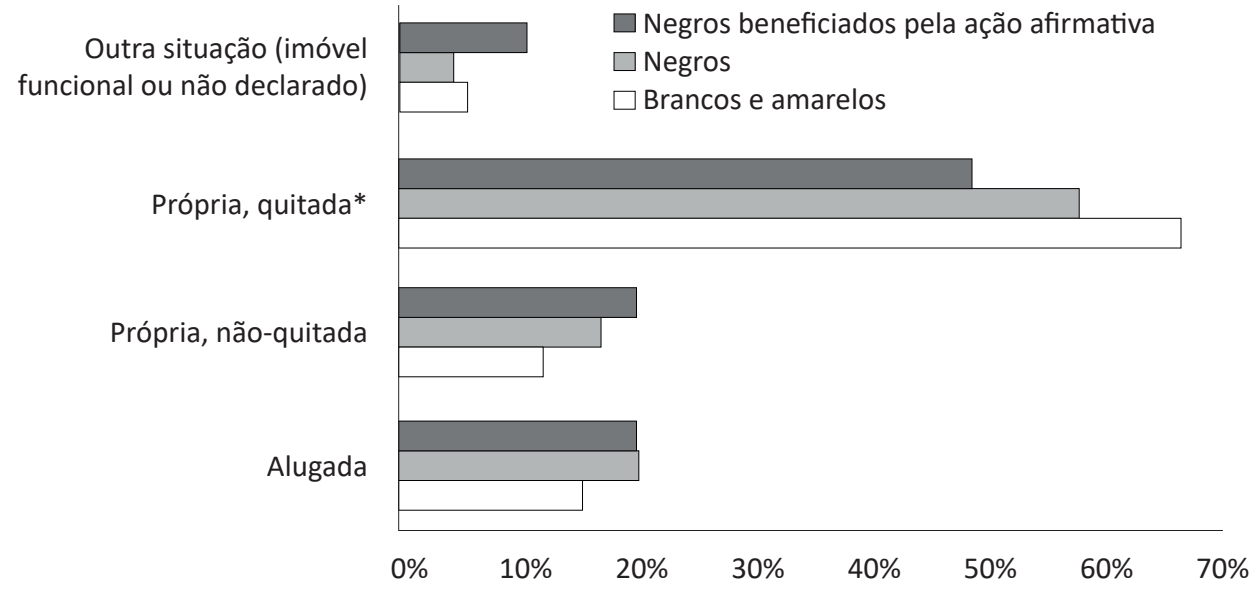

Fonte: elaboração própria.

* Proporções significativamente diferentes $(p<0,05)$ das proporções registradas entre o grupo brancos e amarelos e o grupo negros beneficiados pela ação afirmativa.

Observa-se que, embora inferior à dos demais candidatos, a proporção de candidatos negros que alcançaram o cargo público por meio da reserva de vagas que possui residência própria, ainda que não quitada, não é baixa $(68,80 \%)$. Apenas $20,18 \%$ deste grupo de candidatos informaram residir em imóveis alugados, o que não reflete a realidade das comunidades mais carentes, sejam elas negras ou não, como pode ser visto na Tabela 4. 
Tabela 4 - Tipo de residência da família

\begin{tabular}{|c|c|c|c|c|c|c|}
\hline \multirow[t]{2}{*}{ Tipo de residência } & \multicolumn{2}{|c|}{$\begin{array}{l}\text { Brancos e } \\
\text { amarelos }\end{array}$} & \multicolumn{2}{|c|}{ Negros } & \multicolumn{2}{|c|}{$\begin{array}{c}\text { Negros } \\
\text { beneficiados } \\
\text { pela ação } \\
\text { afirmativa }\end{array}$} \\
\hline & $\mathrm{n}$ & $\%$ & $\mathrm{n}$ & $\%$ & $\mathrm{n}$ & $\%$ \\
\hline Alugada & 51 & 15,60 & 43 & 20,48 & 22 & 20,18 \\
\hline Própria, não quitada & 40 & 12,23 & 36 & 17,14 & 22 & 20,18 \\
\hline Própria, quitada & 217 & 66,36 & 121 & 57,62 & 53 & 48,62 \\
\hline $\begin{array}{l}\text { Outra situação (imóvel } \\
\text { funcional ou não declarado) }\end{array}$ & 19 & 5,81 & 10 & 4,76 & 12 & 11,01 \\
\hline Total & 327 & & 210 & & 109 & \\
\hline
\end{tabular}

Fonte: elaboração própria.

A Tabela 5 apresenta o nível de escolaridade dos genitores dos candidatos aprovados no concurso público analisado. Os dados demonstram uma ascensão no nível de escolaridade dos candidatos (todos com graduação em nível superior) em relação aos seus genitores. À exceção das mães dos candidatos brancos e amarelos (52,91\%), o percentual de graduados em nível superior (com ou sem pós-graduação) dos genitores dos candidatos (pais e mães) é inferior a $50 \%$.

Tabela 5 - Nível de escolaridade dos genitores (pais e mães)

\begin{tabular}{|c|c|c|c|c|c|c|c|c|c|c|c|c|}
\hline \multirow{3}{*}{ Escolaridade } & \multicolumn{4}{|c|}{ Brancos e amarelos } & \multicolumn{4}{|c|}{ Negros } & \multicolumn{4}{|c|}{$\begin{array}{c}\text { Negros beneficiados pela } \\
\text { ação afirmativa }\end{array}$} \\
\hline & \multicolumn{2}{|c|}{ Pai } & \multicolumn{2}{|c|}{ Mãe } & \multicolumn{2}{|c|}{ Pai } & \multicolumn{2}{|c|}{ Mãe } & \multicolumn{2}{|c|}{ Pai } & \multicolumn{2}{|c|}{ Mãe } \\
\hline & $\mathrm{n}$ & $\%$ & $\mathrm{n}$ & $\%$ & $\mathrm{n}$ & $\%$ & $\mathrm{n}$ & $\%$ & $\mathrm{n}$ & $\%$ & $\mathrm{n}$ & $\%$ \\
\hline Analfabeto & 4 & 1,22 & 1 & 0,31 & 3 & 1,43 & 1 & 0,48 & 2 & 1,83 & 2 & 1,83 \\
\hline $\begin{array}{l}\text { Ensino } \\
\text { fundamental } \\
\text { incompleto }\end{array}$ & 29 & 8,87 & 28 & 8,56 & 32 & 15,24 & 21 & 10,00 & 21 & 19,27 & 18 & 16,51 \\
\hline $\begin{array}{l}\text { Ensino } \\
\text { fundamental } \\
\text { completo }\end{array}$ & 30 & 9,17 & 21 & 6,42 & 22 & 10,48 & 23 & 10,95 & 8 & 7,34 & 16 & 14,68 \\
\hline Ensino médio & 101 & 30,89 & 104 & 31,80 & 70 & 33,33 & 66 & 31,43 & 49 & 44,95 & 37 & 33,94 \\
\hline
\end{tabular}




\begin{tabular}{|c|c|c|c|c|c|c|c|c|c|c|c|c|}
\hline Superior & 130 & 39,76 & 133 & 40,67 & 70 & 33,33 & 87 & 41,43 & 20 & 18,35 & 31 & 28,44 \\
\hline Pós-graduado & 32 & 9,79 & 40 & 12,23 & 13 & 6,19 & 12 & 5,71 & 8 & 7,34 & 5 & 4,59 \\
\hline $\begin{array}{l}\text { Não } \\
\text { declarado }\end{array}$ & 1 & 0,31 & 0 & 0,00 & 0 & 0,00 & 0 & 0,00 & 1 & 0,92 & 0 & 0,00 \\
\hline Total & 327 & & 327 & & 210 & & 210 & & 109 & & 109 & \\
\hline
\end{tabular}

O Gráfico 4 apresenta as proporções entre os níveis de escolaridade dos pais dos candidatos aprovados no concurso público analisado. Verificou-se a existência de diferença significativa entre a escolaridade dos pais dos candidatos brancos e amarelos e a dos pais dos candidatos negros beneficiados pela reserva de vagas, sendo constatado um menor nível de escolaridade entre os pais destes últimos candidatos, especialmente em relação àqueles que possuem o ensino médio e o ensino fundamental incompleto $\left(\chi^{2}(10)=27,61 ; p<0,05\right)$.

\section{Gráfico 4 - Nível de escolaridade dos pais dos candidatos}

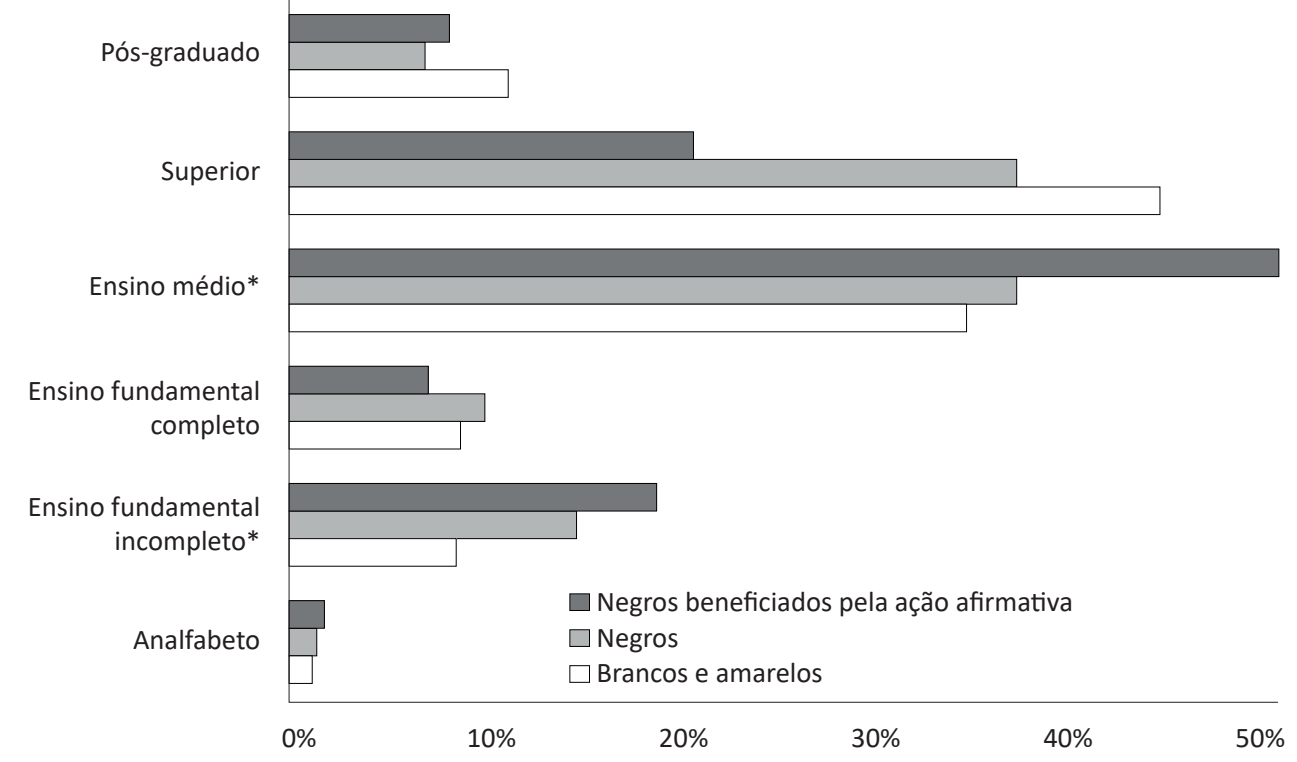

Fonte: elaboração própria.

* Proporções significativamente diferentes $(p<0,05)$ das proporções registradas entre os candidatos brancos e amarelos e os candidatos negros beneficiados pela ação afirmativa. 
Observa-se na Tabela 5 que o nível de escolaridade das mães dos candidatos é mais alto, existindo uma maior proporção de genitoras com nível superior que dos pais dos candidatos. Quando comparados os três grupos de candidatos, verificou-se que as mães dos candidatos brancos e amarelos possuem maior nível de escolaridade que as dos demais grupos e que as mães dos candidatos negros beneficiados pela ação afirmativa possuem menor nível de escolaridade.

Nesse sentido, como pode ser observado no Gráfico 5, os testes estatísticos aplicados $\left(\chi^{2}(10)=27,80 ; p<0,05\right)$ indicaram uma diferença significativa entre as mães dos candidatos brancos e amarelos e os candidatos negros (beneficiados ou não pela ação afirmativa) que possuem pós-graduação. Foi verificado que entre as mães dos candidatos negros há menor proporção de pós-graduadas. De igual maneira foi verificada diferença significativa de escolaridade entre a mães dos candidatos brancos e amarelos e dos candidatos negros beneficiados pela reserva de vagas em relação à proporção de mães que possuem apenas o ensino fundamental completo.

\section{Gráfico 5 - Nível de escolaridade das mães dos candidatos}

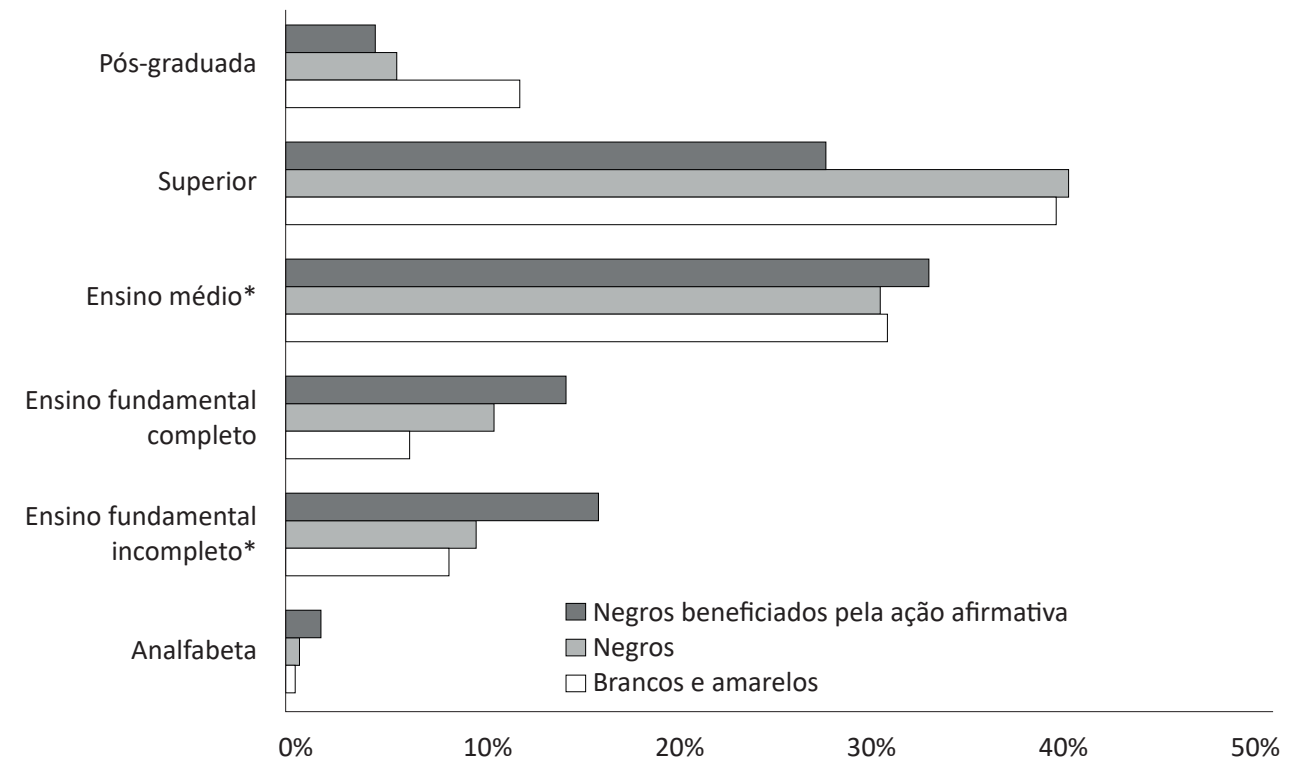

Fonte: elaboração própria.

* Proporções significativamente diferentes $(p<0,05)$ das proporções registradas entre o grupo brancos e amarelos e o grupo negros beneficiados pela ação afirmativa.

† Proporções significativamente diferentes $(p<0,05)$ das proporções registradas entre o grupo brancos e amarelos e o grupo negros.

Em relação ao tipo de estabelecimento de ensino onde os candidatos cursaram o ensino médio, verifica-se um equilíbrio entre o grupo de brancos e amarelos e 
o de negros aprovados na ampla concorrência do concurso público, no tocante à proporção daqueles que cursaram integralmente, ou em sua maior parte, o ensino médio em escolas particulares (63,91\% e 64,76\%, respectivamente), como pode ser observado na Tabela 6.

Os negros beneficiados pela reserva de vagas possuem menor percentual de indivíduos que estudaram integralmente, ou em sua maior parte, em escolas particulares no ensino médio do que os demais grupos (52,29\%). Apesar de inferior, os testes estatísticos aplicados não apresentaram diferença significativa $\left(\chi^{2}(6)=\right.$ $8,83 ; p>0,05)$. Tal constatação demonstra que parcela considerável da população beneficiada pela ação afirmativa teve acesso a escolas particulares em proporção superior à grande parte da comunidade negra brasileira, que se encontra em situação de pobreza.

Tabela 6 - Tipo do estabelecimento de ensino onde o candidato cursou o ensino médio

\begin{tabular}{lcccccc}
\hline & Brancos e & Negros & \multicolumn{3}{c}{$\begin{array}{c}\text { Negros } \\
\text { beneficiados } \\
\text { pela ação } \\
\text { Tipo de Estabelecimento }\end{array}$} & $\begin{array}{l}\text { amarelos } \\
\text { afirmativa }\end{array}$ \\
\cline { 2 - 8 } & $\mathrm{n}$ & $\%$ & $\mathrm{n}$ & $\%$ & $\mathrm{n}$ & $\%$ \\
\hline Todo em escola pública & 93 & 28,44 & 65 & 30,95 & 46 & 42,20 \\
\hline Maior parte em escola pública & 23 & 7,03 & 9 & 4,29 & 6 & 5,50 \\
\hline Maior parte em escola particular & 22 & 6,73 & 16 & 7,62 & 6 & 5,50 \\
\hline Todo em escola particular & 187 & 57,19 & 120 & 57,14 & 51 & 46,79 \\
\hline Não declarado & 2 & 0,61 & 0 & 0,00 & 0 & 0,00 \\
\hline Total & 327 & & 210 & & 109 & \\
\hline
\end{tabular}

Fonte: elaboração própria.

No tocante ao acesso ao ensino superior, se verifica (Tabela 7) que o percentual de candidatos que estudaram integralmente em faculdades ou universidades públicas é mais próximo entre os três grupos de candidatos do que a proporção do acesso a escolas particulares, o que pode ser reflexo das ações afirmativas voltadas para o ingresso de negros em instituições públicas de ensino superior, implementadas há mais de 10 anos, como citado anteriormente. Os testes estatísticos aplicados não apontaram a existência de diferença significativa entre os grupos de candidatos $\left(\chi^{2}\right.$ (8) $=5,89 ; p>0,05)$.

Verifica-se, ainda assim, que o grupo de candidatos beneficiados pela reserva de vagas apresenta um acesso maior a instituições de ensino superior particulares 
e menor em relação às suas congêneres públicas, mantendo-se a tendência desse grupo de apresentar índices socioeconômicos inferiores aos demais grupos.

Tabela 7 - Tipo do estabelecimento de ensino superior onde o candidato se graduou

\begin{tabular}{|c|c|c|c|c|c|c|}
\hline \multirow[t]{2}{*}{ Tipo de estabelecimento: } & \multicolumn{2}{|c|}{$\begin{array}{l}\text { Brancos e } \\
\text { amarelos }\end{array}$} & \multicolumn{2}{|c|}{ Negros } & \multicolumn{2}{|c|}{$\begin{array}{c}\text { Negros } \\
\text { beneficiados } \\
\text { pela ação } \\
\text { afirmativa }\end{array}$} \\
\hline & $\mathrm{n}$ & $\%$ & $\mathrm{n}$ & $\%$ & $\mathrm{~N}$ & $\%$ \\
\hline $\begin{array}{l}\text { Todo em universidade/ } \\
\text { faculdade particular }\end{array}$ & 156 & 47,71 & 99 & 47,14 & 62 & 56,88 \\
\hline $\begin{array}{l}\text { Maior parte em universidade/ } \\
\text { faculdade particular }\end{array}$ & 6 & 1,83 & 7 & 3,33 & 2 & 1,83 \\
\hline $\begin{array}{l}\text { Maior parte em universidade/ } \\
\text { faculdade pública }\end{array}$ & 8 & 2,45 & 4 & 1,90 & 1 & 0,92 \\
\hline $\begin{array}{l}\text { Todo em universidade/ } \\
\text { faculdade pública }\end{array}$ & 154 & 47,09 & 100 & 47,62 & 44 & 40,37 \\
\hline $\begin{array}{l}\text { Em universidade/faculdade } \\
\text { do exterior }\end{array}$ & 1 & 0,31 & 0 & 0,00 & 0 & 0,00 \\
\hline Não declarado & 2 & 0,61 & 0 & 0,00 & 0 & 0,00 \\
\hline Total & 327 & & 210 & & 109 & \\
\hline
\end{tabular}

Fonte: elaboração própria.

\section{Conclusões e recomendações}

A literatura acerca das políticas de ação afirmativa para negros no Brasil demonstra a importância do tema para a redução da discriminação racial e da diferença socioeconômica entre os "grupos raciais" presentes no país. As desigualdades se refletem nos padrões de inserção no mercado de trabalho, especialmente no acesso aos cargos e empregos públicos.

O presente artigo buscou efetuar um balanço inicial da ação afirmativa implementada por meio da Lei Federal $n^{\circ} 12.990 / 2014$, verificando o efeito da reserva de vagas para negros em concursos públicos na composição do perfil racial dos candidatos aprovados em processo seletivo promovido pela Polícia Federal. 
Com base nos dados encontrados, é possível afirmar que houve alteração significativa do perfil racial dos candidatos aprovados no concurso público promovido pela organização. A composição racial dos candidatos aprovados no primeiro concurso público realizado após a implementação da ação afirmativa foi diferente dos certames analisados, realizados antes da edição da Lei $n^{\circ} 12.990 / 2014$, se aproximando do perfil racial da população brasileira, que era o objetivo do projeto de lei que Ihe deu origem ( $P L n^{\circ}$ 6.738/2013). Foi constatado, também, o aumento do número de candidatos pardos que passaram a se declarar negros.

Quando comparado o perfil socioeconômico de brancos e amarelos com os negros que foram aprovados no concurso e com os negros que foram beneficiados pela reserva de vagas, verificou-se que estes últimos possuem, em média, renda familiar menor, maior quantidade de moradias em imóveis alugados, nível de escolaridade dos pais mais baixo, menor acesso às escolas privadas no ensino médio e menor acesso ao ensino superior público.

No entanto, observando-se esses mesmos índices, é possível verificar que o benefício gerado pela ação afirmativa alcançou em menor escala os indivíduos oriundos da comunidade negra mais pobre, tendo em vista que $71,55 \%$ dos beneficiados pela reserva de vagas possuem renda familiar superior a 5 salários, $48,62 \%$ possuem casa própria e $46,79 \%$ tiveram acesso a escolas particulares no ensino médio, que são índices que não se coadunam com os vivenciados pela camada mais baixa da população.

Tal constatação vai ao encontro do exposto por Haas e Linhares (2012) quando afirmaram que, em razão das deficiências na formação básica associadas a práticas discriminatórias, as ações afirmativas que visam a facilitar o acesso aos cursos superiores por meio de cotas para candidatos negros não beneficiam os negros pobres, que vivem nos limites da pobreza e não possuem qualquer aspiração ao curso superior, uma vez que os cargos referentes aos processos seletivos avaliados possuem como requisito justamente a graduação em nível superior, que é pouco alcançada pelos negros mais pobres.

A reserva de vagas em concurso público está em vigor há pouco mais de 2 anos. É de fundamental importância o estabelecimento de procedimentos aplicados com frequência para monitorar e avaliar a eficácia da ação afirmativa em pauta. A obtenção de dados sobre a sua implementação é imprescindível para o seu aperfeiçoamento por meio de contínuo processo de avaliação e reformulação das suas premissas, métodos e procedimentos caso os resultados apontem para a necessidade de modificações na política de ação afirmativa.

Embora existam inúmeros estudos publicados acerca da reserva de vagas para negros em instituições de ensino superior, não foram encontradas, na literatura 
nacional, publicações que tenham avaliado os efeitos da reserva de vagas para a população negra em concursos públicos. Desse modo, ante a lacuna verificada na literatura, espera-se que os dados empíricos apresentados no presente artigo contribuam para o acompanhamento e avaliação da ação afirmativa.

Para além das conclusões acima, se faz necessário registrar algumas lacunas deste estudo, que se constituem em novas pautas para a aplicação de pesquisas. Com base nos censos demográficos, foi constatada uma alteração na configuração racial da população brasileira entre os anos 2000 e 2010, verificando-se maior presença de negros quando comparados com os brancos no total da população, tendo ocorrido o aumento do número de pessoas que se declararam pretos ou pardos (ARTES; RICOLDI, 2015).

Segundo Soares (2008), tal fenômeno pode ser entendido não somente em razão da diferença da taxa de fecundidade entre os "grupos raciais", mas principalmente em razão da tendência do aumento do número de pardos e pretos que se identificam como negros. Para o autor, o país não está se tornando uma nação de negros, mas se assumindo como tal, o que pode ser uma explicação para o aumento substancial da quantidade de candidatos pardos que se declararam negros, observado no presente estudo.

Por outro lado, é possível que a mudança da declaração quanto à cor/raça possa ser decorrente do interesse em ser beneficiado pela ação afirmativa e não necessariamente pela vontade de se assumir enquanto integrante da comunidade negra, uma dúvida aventada por Rosemberg (2004) quando levantou o questionamento se o branco das pesquisas do IBGE continuava branco quando submetido a questionário para ser utilizado em um programa de ação afirmativa direcionado a negros e indígenas, o que também pode ter tido reflexo nos dados obtidos.

Essas questões não foram aprofundadas no presente estudo. Determinar quanto e em que aspectos a mudança do perfil racial dos aprovados em concursos públicos após a implementação da reserva de vagas decorreu da política de ação afirmativa ou de outros fatores socioeconômicos é um caminho a ser trilhado, o que requer novos estudos para seu desvelamento.

Em última análise, a mensuração dos resultados da ação afirmativa em tela demonstrou a importante alteração do perfil racial dos aprovados no concurso público da Polícia Federal após a implementação da reserva de vagas para negros. O levantamento desses dados é indispensável para aperfeiçoar o debate e subsidiar decisões políticas sobre tema tão complexo e polêmico, mas fundamental para o Estado brasileiro, que é a inclusão de segmentos desprivilegiados e discriminados da população brasileira. 


\section{Referências bibliográficas}

Alberti, Verena; PereirA, Amilcar. A defesa das cotas como estratégia política do movimento negro contemporâneo. Estudos Históricos, Rio de Janeiro, n. 37, p. 143166, jan./jun. 2006.

Albrecht, Pricila Anny Tomachski; KraWulski, Edite. Concurseiros e a busca por um emprego estável: reflexões sobre os motivos de ingresso no serviço público. Cadernos de Psicologia Social do Trabalho, v. 14, n. 2, p. 211-226, dez. 2011.

ANDREWS, George Reid. Ação afirmativa: um modelo para o Brasil? In: SouzA, Jessé. (Org.). Multiculturalismo e racismo: uma comparação Brasil-Estados Unidos. Brasília: Paralelo 15, 1997. p. 137-144.

ANJos, Gabriele dos. A questão "cor" ou "raça" nos censos nacionais. Indicadores Econômicos FEE, v. 41, p. 103-118, 2013.

ARTES, Amélia; RIColdi, Arlene Martinez. Acesso de negros no ensino superior: o que mudou entre 2000 e 2010. Cadernos de Pesquisa, São Paulo, v. 45, n. 158, p. 858-881, dez. 2015.

Azevedo, Célia Maria Marinho. Cota racial e Estado: abolição do racismo ou direitos de raça? Cadernos de Pesquisa, v. 34, p. 213-239, jan./abr. 2004.

BRASIL. Lei Federal no 12.990, de 9 de junho de 2014. Reserva aos negros 20\% (vinte por cento) das vagas oferecidas nos concursos públicos para provimento de cargos efetivos e empregos públicos no âmbito da administração pública federal, das autarquias, das fundações públicas, das empresas públicas e das sociedades de economia mista controladas pela União. Brasília: Planalto, 2014.

Cammarosano, Márcio. Provimento de cargos públicos no Direito brasileiro. São Paulo: Revista dos Tribunais, 1984.

CARVAlHo, José Jorge de. Uma proposta de cotas para estudantes negros na Universidade de Brasília. Brasília: UnB, 2001.

CARVALHO, José Jorge de. As ações afirmativas como resposta ao racismo acadêmico e seu impacto nas ciências sociais brasileiras. Teoria e Pesquisa, São Carlos, v. 42-43, p. 103-340, jan./jul. 2003.

CASTELAR, Ivan; Veloso, Alexandre Weber Aragão; FerReIRA, Roberto Tatiwa; SoARES, Ilton. Uma análise dos determinantes de desempenho em concurso público. Econ. Apl., Ribeirão Preto, v. 14, n. 1, p. 81-98, Mar. 2010.

Conselho Nacional de Justiça (CNJ). Censo do Poder Judiciário: Vide - Vetores Iniciais e Dados Estatísticos. Brasília: CNJ, 2014.

CONTINS, Márcia; SANT'ANA, Luiz Carlos. O movimento negro e a questão da ação afirmativa. Estudos Feministas, IFCS/UFRJ-PPCIS/Uerj, v. 4, n. 1, p. 209-220, 1996. CostA, Frederico Lustosa da. Brasil: 200 anos de Estado; 200 anos de administração pública; 200 anos de reformas. Rev. Adm. Pública, Rio de Janeiro, v. 42, n. 5, p. 829874, out. 2008.

CUNHA, Estela Maria Garcia Pinto. Brasil está reduzindo suas disparidades raciais? In: Encontro Nacional de Estudos Populacionais, 18., 2012. Anais... Abep, 2012. 
DAFLON, Verônica Toste; FERES JUNIOR, João; CAMPOS, Luiz Augusto. Ações afirmativas raciais no ensino superior público brasileiro: um panorama analítico. Cadernos de Pesquisa, São Paulo, v. 43, n. 148, p. 302-327, abr. 2013.

DOMINGUES, Petrônio. Ações afirmativas para negros no Brasil: o início de uma reparação histórica. Rev. Bras. Educ, Rio de Janeiro, n. 29, p. 164-176, ago. 2005.

Escola nacional de Administração Pública (EnAP). Estudos, Servidores Públicos Federais - Raça/Cor. Brasília: Enap, 2014.

ESTANISLAU, Bárbara; GOMOR, Eduardo; NAIME, Jessica. A inserção dos negros no serviço público federal e as perspectivas de transformação a partir da Lei de Cotas. Cadernos ENAP, v. 42, p. 107-132, 2015.

FERES JÚNIOR, João. Ação afirmativa: política pública e opinião. Sinais Sociais, v. 3, p. 38-77, 2008.

FERES JUNIOR, João; DAFLON, Verônica Toste. A nata e as cotas raciais: genealogia de um argumento público. Opin. Publica, Campinas, v. 21, n. 2, p. 238-267, ago. 2015a. FERES JUNIOR, João; DAFLON, Verônica Toste. Ação afirmativa na Índia e no Brasil: um estudo sobre a retórica acadêmica. Sociologias, Porto Alegre, v. 17, n. 40, p. 92-123, dez. 2015b.

FontAinha, Fernando de Castro; Geraldo, Pedro Heitor Barros; Veronese, Alexandre; ALVES, Camila Souza. O concurso público brasileiro e a ideologia concurseira. Revista Jurídica da Presidência, v. 16, p. 671-702, 2015.

FRY, Peter. Ciência social e política "racial" no Brasil. Revista da USP, São Paulo, n. 68, p. $180-187$, dez./fev. 2006.

GoMES, Joaquim Barbosa. A recepção do instituto da ação afirmativa pelo Direito Constitucional brasileiro. In: SANTOS, S. A. (Org.). Ações afirmativas e combate ao racismo nas Américas. Brasília: Ministério da Educação, Secad, 2005a. p. 47-82.

GoMES, Nilma Lino. Alguns termos e conceitos presentes no debate sobre relações raciais no Brasil: uma breve discussão. In: HENRIQUES, Ricardo (Org.). Educação anti-racista: caminhos abertos pela Lei Federal no 10.639/03. Brasília: Secad/MEC, 2005b.

GuARNierı, Fernanda Vieira; Melo-Silva, Lucy Leal. Ações afirmativas na educação superior: rumos da discussão nos últimos cinco anos. Psicol. Soc., Porto Alegre, v. 19, n. 2, p. 70-78, ago. 2007.

GUIMARÃES, Antônio Sérgio Alfredo. Políticas públicas para a ascensão dos negros no Brasil: argumentando pela ação afirmativa. Afro-Ásia, n. 18, p. 235-264, 1996.

GUIMARÃES, Antônio Sérgio Alfredo. Entrevista com Carlos Hasenbalg. Tempo soc., São Paulo, v. 18, n. 2, p. 259-268, nov. 2006.

HAAS, Celia Maria; LINHARES, Milton. Políticas públicas de ações afirmativas para ingresso na educação superior se justificam no Brasil? Rev. Bras. Estud. Pedagog., Brasília, v. 93, n. 235, p. 836-863, dez. 2012.

HERINGER, Rosana. Mapeamento de ações e discursos de combate às desigualdades raciais no Brasil. Estud. afro-asiát., Rio de Janeiro, v. 23, n. 2, p. 1-43, 2001. 
Instituto Brasileiro de Geografia e Estatística (IBGE). Pesquisa Nacional por Amostra de Domicílios. Síntese dos Indicadores de 2014. Rio de Janeiro: IBGE, 2015. LIMA, Márcia. Desigualdades raciais e políticas públicas: ações afirmativas no governo Lula. Novos estud. - CEBRAP, São Paulo, n. 87, p. 77-95, jul. 2010.

LORENZO, Rocío Alonso. As ações afirmativas para afrodescendentes articuladas a partir de parcerias intersetoriais: uma análise argumentativa do caso Geração XXI. Organ. Soc., Salvador, v. 19, n. 63, p. 697-713, dez. 2012.

LoVEMAN, Mara; MunIz, Jeronimo. O.; BAILEY, Stanley. R. Brazil in black and white? Race categories, the census and the study of inequality. Ethnic and racial studies, $\mathrm{v}$. 35, n. 8, set. 2011.

MAIO, Marcos Chor; SAnTOS, Ricardo Ventura. Política de cotas raciais, os "olhos da sociedade" e os usos da antropologia: o caso do vestibular da Universidade de Brasília (UnB). Horiz. antropol., Porto Alegre, v. 11, n. 23, p. 181-214, jun. 2005.

MARConI, Nelson. A evolução do perfil da força de trabalho e das remunerações nos setores público e privado ao longo da década de 1990. Revista do Serviço Público, ano 54, n. 1, p. 7-43, jan.-mar. 2003

MARTINS, Sérgio da Silva. Ação afirmativa e desigualdade racial no Brasil. Estudos Feministas. IFCS/ UFRJ-PPCIS/Uerj, v. 4, n. 1, p. 202-208, 1996.

Mendes Junior, Álvaro Alberto Ferreira; Waltenberg, Fábio Domingues. Políticas de cotas não raciais aumentam a admissão de pretos e pardos na universidade? Planejamento e Políticas Públicas, n. 44, p. 229-256, 2013.

Moenlecke, Sabrina. Ação afirmativa: história e debates no Brasil. Cadernos de Pesquisa, n. 117, p. 197-217, nov. 2002.

Moura, Carlos Alves; BARreto, Jônatas Nunes. A Fundação Cultural Palmares na III Conferência Mundial de Combate ao Racismo, Discriminação Racial, Xenofobia e Intolerância Correlata. Brasília: Fundação Cultural Palmares (FCP), 2002.

NogueIRA, Roberto Passos. Novas tendências internacionais da força de trabalho do setor público: o Brasil comparado com outros países. Brasília: Universidade de Brasília, 2005.

OlIVEIRA, Clarice Gomes. O servidor público brasileiro: uma tipologia da burocracia. Revista do Serviço Público, v. 58, p. 269-302, 2007.

OliveIRA, Dijaci David de; LIMA, Ricardo Barbosa de; SAntos, Sales Augusto dos. A cor do medo: o medo da cor. In: OliveirA, Dijaci David de et al. (Orgs.). A cor do medo. Homicídios e relações raciais no Brasil. Brasília: Editora da UnB, Goiânia: Editora da UFG, 1998.

OsóRıO, Rafael. O sistema classificatório de cor ou raça do IBGE. Brasília: Ipea, TD n 996, 2003.

Pereira, Sueli Menezes; ZientARSKı, Clarice. Políticas de ações afirmativas e pobreza no Brasil. Revista Brasileira de Estudos Pedagógicos (Impresso), v. 92, p. 493-515, 2011.

PIOVESAN, Flávia. Ações afirmativas da perspectiva dos Direitos Humanos. Cadernos de Pesquisa, v. 35, n. 124, p. 43-55, jan./abr. 2005. 
RAmalho Neto, Jaime P. Farda \& "cor": um estudo racial nas patentes da polícia militar da Bahia. Afro-Ásia, Salvador, n. 45, p. 67-94, 2012.

Ribeiro, Carla Vaz dos Santos; MAnCebo, Deise. O servidor público no mundo do trabalho do século XXI. Psicol. Cienc. Prof., Brasília, v. 33, n. 1, p. 192-207, 2013.

Ribeiro, Carla Vaz dos Santos; MAncebo, Deise. Concurso público, uma alternativa sensata frente às turbulências do mundo do trabalho? Trabalho \& Educação (UFMG), v. 18, p. 145-156, 2009.

ROSEMBERG, Fúlvia. O branco do IBGE continua branco na ação afirmativa? Estudos Avançados, São Paulo, v. 18, n. 50, p. 225-241, 2004.

SANTOS, Jocélio Teles dos. Ações afirmativas e educação superior no Brasil: um balanço crítico da produção. R. bras. Est. pedag., Brasília, v. 93, n. 234, [número especial], p. 401-422, mai./ago. 2012.

SANTOS, Sales Augusto dos. Ação afirmativa ou a utopia possível: o perfil dos professores e dos pós-graduandos e a opinião destes sobre ações afirmativas para os negros ingressarem nos cursos de graduação da UnB. Relatório Final de Pesquisa. Brasília: ANPED/ $2^{\circ}$ Concurso Negro e Educação, mimeo, 2002.

SANTOS, Sales Augusto dos; SILVA, Nelson Inocêncio Olokafá da. Brazilian indifference to racial inequality in the labor market. Latin American Perspectives, California, issue 149, v. 33, n. 4, p. 13-29, jul. 2006.

SAntos, Sônia Querino dos Santos; MAChado, Vera Lúcia de Carvalho. Políticas públicas educacionais: antigas reivindicações, conquistas (Lei 10.639) e novos desafios. Ensaio: aval.pol.públ.Educ, Rio de Janeiro, v. 16, n. 58, p. 95-112, mar. 2008.

SCHWARTZMAN, Simon. Fora de foco: diversidade e identidades étnicas no Brasil. Novos Estudos CEPRAP, São Paulo, n. 54, p. 83-96, 1999.

SILVA, Josélia Rita da; BALASSIANO, Moisés; SILVA, Alfredo Rodrigues Leite da. Burocrata proteano: articulações de carreira em torno e além do setor público. Rev. adm. contemp., Curitiba, v. 18, n. 1, p. 01-19, fev. 2014.

SILVA, Mariléia Maria da. O trabalho para jovens graduados no novo modelo de acumulação capitalista. Perspectiva, Florianópolis, v. 22, n. 02, p. 405-424, jul./dez. 2004.

SILVA, Tatiana Dias. O Estatuto da Igualdade Racial. Rio de Janeiro: Ipea, TD n 1.712, 2012.

SILVA, Tatiana Dias; SILVA, Josenilton Marques da. Reserva de vagas para negros em concursos públicos: uma análise a partir do Projeto de Lei 6.738/2013. Nota técnica, n. 17, fev. 2014.

SIlveIRA, Conselheiro Fabiano. Cotas raciais para concurso de ingresso na magistratura. RDA - Revista de Direito Administrativo, Rio de Janeiro, v. 270, p. 363373, set./dez., 2015

SOARES, Sergei. A demografia da cor: a composição da população brasileira de 18902007. In: THEOdoRo, Mário. (Org.). As políticas públicas e a desigualdade racial no Brasil: 120 anos após a abolição. Brasília, DF: IPEA, 2008. p. 97-117. 
SOUSA, Letícia Pereira; PORTES, Écio Antônio. As propostas de políticas/ações afirmativas das universidades públicas e as políticas/ações de permanência nos ordenamentos legais. Revista Brasileira de Estudos Pedagógicos, Brasília, v. 92, n. 232, p. 516-541, set./dez. 2011.

SouzA, Pedro Herculano Guimarães Ferreira de; MedeIRos, Marcelo. Diferencial salarial público-privado e desigualdade de renda per capita no Brasil. Estud. Econ., São Paulo, v. 43, n. 1, p. 05-28, mar. 2013.

TRAgtenberg, Marcelo Henrique Romano. Um olhar branco sobre ações afirmativas. Revista Espaço Acadêmico, Maringá: UEM, a. II, n. 13, jun. 2002.

VALLE Silva, Nelson do. Uma nota sobre "raça social" no Brasil. In: HASENBALG, Carlos Alfredo; VAlle SILVA, Nelson do; LIMA, Márcia. (Orgs.). Cor e estratificação social. Rio de Janeiro: Editora Contracapa, 1999.

WALTERS, Ronald. Racismo eaçãoafirmativa. In:SouZA, Jessé. (Org.).Multiculturalismo e racismo: uma comparação Brasil-Estados Unidos. Brasília: Paralelo 15, 1997. p. 105-123.

Wood, Charles. H.; CARVAlHo, José Alberto Magno de: HorTA, Cláudia Júlia Guimaraes. The color of child mortality in Brazil, 1950-2000: social progress and persistent racial inequality. Latin American Research Review, v. 45, n. 2, p. 114-139, 2010.

\section{Andersson Pereira dos Santos}

Doutorando em Administração pela Universidade de Brasília (UnB) e mestrado em Administração Pública pela mesma universidade. Atualmente é delegado de Polícia Federal. Contato: andersson.aps@dpf.gov.br

\section{Gilson Matilde Diana}

Doutorando em Direito pela Universidade de Brasília (UnB), mestre em Filosofia pela mesma universidade. Atualmente é Técnico em Assuntos Educacionais da Academia Nacional de Polícia. Contato: gilson.gmd@dpf.gov.br 
RSP 